\title{
GUS VAN SANT E A IMAGEM-NÉVOA
}

\author{
Rafael Dias
}

As nuvens constituem um motif ${ }^{42}$ poético do cineasta norte-americano Gus Van Sant. Elas instauram um cinema profundamente (climatérique) climatérico (BOUQUET; LALANNE, 2009, p.38), no qual o tempo se sobrepõe ao espaço via imagens que equivalem a uma transubstanciação do real. As digressões - que dizem respeito não somente a nuvens que cortam o céu, matéria leve, mas a outros fenômenos visíveis aos nossos olhos, como o sol ao cair no entardecer, variações da luz sobre uma estrada, a noite que cai compõem um esforço imagético em capturar intersecções do tempo, ato levado a efeito (ou tencionado) tecnicamente a partir do uso de recursos como slowmotion, time-lapse e planos-sequências dilatados.

O ecrã vansantiano, em alguns casos, segue um fluxo de imagens em que o sobrenarrativo, aquilo que está acima da cabeça das personagens, é tão importante quanto o que é captado na tessitura das relações humanas: um reflete o outro numa relação de duplo versus ausência. A efeito deste artigo, iremos analisar como Van Sant trabalha a névoa como espectro da realidade, às vezes como um ultrapassamento dela, outras como um duplo fantasmagórico. O corpus de observação será Últimos Dias (Last Days), de 2005, com produção pela HBO Films, longa que faz um decupagem livre dos dias que antecederam o suicídio de Kurt Cobain, encontrado morto em 8 de abril de 1994, em sua casa em Seattle, nos Estados Unidos.

A névoa é uma chave interpretativa, epítome poético que dialoga em um escopo de abstração, remetendo aqui a uma questão conceitual. Ela advém diretamente do elemento "nuvem", massa gasosa, mas também pode ser entendida como superfície invisível e etérea. Algo que nos cega, interrompe nossa visão, revelando algo posterior em sua imagem atual. Na literatura, tomamos como partida a metáfora da "névoa da palavra" do poeta pérsio Mowlânâ (apud CARRIÉRE, 2006, p; 196), traduzida para os dias atuais por Carrière como a "bruma acumulada sobre a bruma":

$42 \mathrm{O}$ uso do termo motif ("motivo", em francês) afasta a imprecisão em situar a fala em questões de tendência ou gênero, seguindo a mesma terminologia usada por Bouquet e Lalanne. Concordamos com os autores, no sentido de que as nuvens enfeixam menos uma recorrência estilística ou uma consciência de um gesto criador em Van Sant que uma sensibilidade da imagem. 
As imagens filmadas (justamente porque o cinema parece tão perfeito, pois não parece uma máscara) talvez sejam as mais ilusórias de todas as máscaras que colocamos sobre o rosto da realidade. E, ainda assim, quando um filme nos toma por completo, as imagens que sabemos falsas podem nos levar a uma realidade superior, mais forte, mais penetrante, e decisivamente mais real do que a própria realidade (CARRIÈRE, 2006, p.196).

O cinema pode ser um portal para a epifania. Assim, podemos chegar ao conceito da imagem-névoa, aquela que se reveste da bruma para fazer-se enxergar, para elucidar nosso pensamento em meio ao nevoeiro da razão, condensando o tempo presente da imagem em constante mudança (a nuvem, o movimento) com aquilo que ela traz de atualização, passado ou futuro (o tempo congelado, acelerado, duplicado e múltiplo). Para a análise das imagens, usaremos a metodologia das molduras de Suzana Kilpp, com base nos pensamentos da imagem-duração de Henri Bergson e da imagem-tempo de Gilles Deleuze, acionados pela pesquisadora gaúcha. Vale destacar que o encadeamento dos quadros de Últimos Dias, assim como o de Elefante, de 2003, outro filme de Van Sant exatamente anterior, é fraturado pela repetição. O filme de nossa análise mostra situações em que o músico Blake, interpretado pelo ator Michael Pitt, ensaia ou sucumbe a crises, com cenas que se repetem sob dois ou mais pontos de vista, marcando uma narrativa circular e labiríntica. As nuvens, junto à quase anulação narrativa, contrapõem-se como um sublime fotográfico ao simples registro da morte da matéria. Em Últimos Dias, como demonstraremos adiante, a nuvem se faz imagem-névoa a partir de superfícies refletoras e da desaparição do próprio ente gasoso. Ela, feita de luz, vira o movimento em si.

Com efeito, a imagem-névoa manifesta-se no espaço circunscrito de uma moldura, um "devir-janela" (KILPP, 2009, p. 13), o que nos remete à imagem reflexiva e a ideia de contemplação. A utilização do artifício metodológico de Kilpp ${ }^{43}$ consiste em apreender as relações entre o tempo do filme (a agonia lenta de um músico viciado em drogas que resvala até a morte) e o tempo que circunda o objeto de nossa fruição do olhar, problematizado pela delicada - e quase imperceptível - intervenção vansantiana. Tal mis en scène, cuja essência é identificada pela imagem-névoa, opta, além dos planos-sequência arrastados e de frames repetidos, pela refração de luzes. Em muitas cenas, como iremos ver adiante, as nuvens são substituídas pelo movimento da copa das árvores, por exemplo. A energia da natureza, como Van Sant registra pelo modo do duplo especular, flui por outro reflexo, o do céu emoldurado pelos galhos, mais próximo às nossas cabeças.

||||||||||||||||||||||||||||||||||||||||||||||||||||||||||||||

43 No artigo Imagens-média do tempo acontecimento, Kilpp afirma que a imagem-duração é uma "natureza precípua" da TV, suporte com a qual se debruça em sua análise como pesquisadora. Ela diz que o fluxo de tempo real da televisão e a montagem superficial de molduras informativas criam uma estética única, segundo ela diferente do cinema e do vídeo, que produziriam apenas imagens de tempo. Discordamos da autora, na medida em que o cinema e o audiovisual também podem criar molduras e diálogos com um tempo sublime. 
Antes de proceder à imagem-névoa e suas particularidades, é preciso fazer uma ressalva. Este artigo não pretende defender uma aplicabilidade da metodologia de Kilpp. $\mathrm{O}$ que nos interessa nela é o olhar específico sobre uma realidade aparentemente banal, ou descartável pelo seu fator corriqueiro, inclusive em práticas fotográficas. Tencionaremos converter a sensibilidade de Kilpp em falar das molduras em análises televisivas ao nosso modo de ver as "molduras de névoa" de Van Sant. A efetividade de seu método dá-se mais numa esfera apreensiva de sua essência que no uso mecânico e meramente residual. Somente para efeito de mais um adendo, também será importante para este arcabouço teórico, já que estamos evocando aqui a fotografia em si como conceito, trazer à luz algumas formulações de Annateresa Fabris sobre identidades visuais e a temporalidade da imagem técnica dentro do campo artístico geral. É fundamental, por exemplo, para avançar na reflexão, pensar a incidência de Andy Warhol e sua desaparição do sujeito, em Últimos Dias. Decerto, o fato de Gus Van Sant ser fotógrafo, além de pintor (estudou na Rhode Island School of Design, nos Estados Unidos, nos anos 1970), contribui também para entender um pouco sobre tal flerte com a imagem estática.

\section{Reflexo e Nuvem}

A nuvem em Gus Van Sant é corte (ato operacional), mas também devir (ato final). Parecem dimensões paradoxais, mas não são: o primeiro não necessariamente origina o segundo, é antes uma condição. O corte vansantiano torna-se devir pela sobreposição. A extração da imagem-névoa, primeiramente, ocorre no plano da realidade: ou de uma atmosfera celeste, ou, em muitos casos, tomando por base os reflexos. Esses últimos, imagens secundárias e mediadas, não se formam unicamente de imagens devolvidas de espelhos, objeto-clichê, convertido em fios de tempo de memória, como já fizeram Tarkovski (O Espelho), Visconti (Morte em Veneza) e Resnais (O ano passado em Marienbad) de maneira que se tornou icônica para o cinema. No entanto, Últimos Dias explora uma abordagem distinta desse grupo no terreno espectral, ainda que bastante incidente no cinema contemporâneo: enfatizar o elemento estético do reflexo a partir de outras superfícies especulares, como o vidro. O diretor taiwanês Hou Hsiao-Hsien é outro cineasta que tem um apreço por esse recurso. É comum o espectro do vidro no filme $A$ viagem do balão vermelho, de 2007, com suas refrações de luz de cafés e bares parisienses. A imagem nasce, assim, do corte pela imagem dupla, ou seja, do enquadramento fílmico do real e sua versão espírito.

A questão do corte é destacada pelo pesquisador Philippe Dubois (apud FABRIS, 2011, p. 69) no pictorialismo fotográfico, vertente artística do fim do século 19. E, por coincidência, ele recorre à nuvem como tema, fazendo uma análise poética no livro $O$ ato fotográfico e Outros Ensaios. O modo como ele fala de fotógrafos daquela época, que tentam compor ao modo de um pintor, nos aponta confluências entre Gus Van Sant e os trabalhos dos fotógrafos Paul Strand e Alfred Stieglitz. Este último, sobretudo, criando 
um dialogismo mais próximo com o diretor norte-americano, pelo fato de ter produzido a série Equivalências (1923-1932), que retratava nuvens transfiguradas em aspectos totalmente abstratos, sem horizonte e com percepção aberta ao mergulho inconsciente. A aproximação Van Sant e Stieglitz não se dá apenas no plano temático (a nuvem): o golpe (o corte) da imagem também se radicaliza na tentativa de configurar uma nova visualidade. De certa forma, Stieglitz e Van Sant são menos adeptos da tentativa de abarcar a realidade em sua completude do que da cisão da imagem. Perfilam-se, assim, em torno de um estado de evanescência, daquilo que lhes escapa ao realismo do dispositivo técnico. Está, aí, um fruto do corte: o extracampo, a ideia de algo que está fora do enquadramento e é preenchido por espaço e tempo imaginários, torna-se uma peça comum entre eles. Stieglitz compôs fotos de nuvens que levavam ao completo delírio, corte tão radical que propõe, segundo Dubois, uma "transformação radical da realidade e estrutura um espaço autônomo que, pela falta de linha do horizonte, destrói todo sentido de orientação" (apud FABRIS, 2011, p. 70). Por sua vez, em Últimos Dias, Van Sant não opera o corte no raccord (falsa ligação) entre os planos, e sim, dentro deles, na relação interna dos elementos que compõem a imagem. A radicalização reside, assim, de outra maneira, no paradoxo da imagem em movimento. Se por um lado a sequência de frames é repetida exaustivamente, por outro a narrativa é readequada ao tempo real, como um reality show, não mais em função de uma filmagem do passado, mas de um estado in progress. Esse olhar tem a particularidade de se focar a uma distância mínima do objeto e de efetuar uma sondagem meticulosa da ação, cumprida pela captura de uma vida que flui em seu tempo cronológico.

Em termos práticos, o cotidiano, filmado em tempo estendido, cria uma relação com a névoa, a bruma que desconcerta pelo excesso de imagem reflexiva ou pelo tempo de exposição. O corte, assim, aparece dentro da imagem, no frame em si, por meio da delimitação de gestos, refutações e expressões faciais de Blake, em situações corriqueiras em sua casa (como preparar um café). No entanto, há ainda o não-corte, o encadeamento fílmico que compõe uma camada por cima: o tempo é dilatado, avança (quando o músico manifesta as primeiras crises de alienação), recua (ao receber a visita de dois missionários mórmons), estanca (quando o músico, novamente, cai no chão e é socorrido por uma das amigas que moram na casa) etc. Todos esses movimentos ondulatórios, sem uma cronologia fundadora, cruzam-se nesse imenso cristal da imagem-névoa: a morte iminente de um astro midiático fechado em si próprio na solidão. O filme fala do degringolamento de um músico, inspirado livremente em Kurt Cobain, ícone do movimento grunge, e a colagem antinarrativa de planos longos (numericamente, isso significa 71 planos em uma hora e 32 minutos de filme) espelha esse sentimento da personagem. A câmera segue um curso vertiginoso, com várias paradas e hesitações em entremeio, algumas muito longas, com até cinco minutos de duração em uma única tomada, levando o espectador ao estado de hipnose pela repetição de som e imagem. As cenas não guardam uma relação de causa-efeito: os ensaios exaustivos de Blake com a guitarra elétrica ou com a bateria; depois, mostra-se o clipe do grupo de r\&b Boys II Men que veicula sem parar na TV; o 
barulho do entra-e-sai de amigos; fluxo que torna ainda sufocante a ambiência de uma casa que funciona como um grande cristal. Atualizados pela matéria dos corpos que ali habitam, tempos múltiplos em sua multiplicidade culminam no último ato, este, sim, cravado no tempo cronológico conhecido, em que Blake se mata com um tiro de espingarda.

Fabris, ao descrever os métodos pictorialistas de Strand e Stieglitz, prega uma objetividade que se assemelha àquela defendida por Van Sant em seu cinema, pontuado por closes-up e recortes da realidade via câmera para atingir uma visão subjetiva da névoa.

\begin{abstract}
A objetividade defendida por Strand implica uma manipulação do mundo pelo aparelho fotográfico, sem que isso signifique uma distorção da realidade. Interessado em buscar seus temas no mundo real, o fotógrafo usa recursos de iluminação, escolhe novos ângulos de visão, aproxima-se do objeto de modo a obter close-ups, com o objetivo de propor um realismo inerente ao aparato e sintonizado com os alcances da arte moderna, sobretudo cubismo e precisionismo. Essas mesmas qualidades são detectadas nas imagens de Stieglitz, que usa a câmara como um instrumento de conhecimento intuitivo, conseguindo resultados que não são oferecidos por outros meios (FABRIS, 2011, p. 57).
\end{abstract}

É importante deixar claro que a relação de Van Sant com o pictorialismo não é automática, tampouco assumida abertamente pelo diretor. A equivalência também é impossível, porque nos referimos a suportes e meios estéticos diferentes, a fotografia e o cinema. No entanto, o cineasta norte-americano, como um pesquisador teórico, fala em um retorno ao cinema silencioso de D. W. Griffith, fazendo alusão a um tipo de produção de imagens associada a valores pictóricos. Há, nesse jogo, um interesse na reapropriação de elementos do belo na fotografia do cinema. E, nesse sentido, ele vai se cercar do cinematógrafo Harry Savides, encarregado de destacar as cores e compor um painel de puro deleite visual. A cor verde dos arbustos e das árvores ao redor da casa de Blake ganha uma tonalidade viva, mesmo dentro dos cômodos, com o reflexo dos jardins que entra pela janela. A camisa suja do protagonista também adquire um tom verde-musgo, dando à atmosfera de Últimos Dias a ideia de um filtro, da máscara da qual Carrière fala. A bruma do excesso de verde refratará a luz do início até a morte de Blake.

A transmutação da personagem ocorre em vários momentos de Últimos Dias. Há uma cena que, em especial, a refração irá persuadir o olhar do espectador para o estado de descolamento carnal. Em crise existencial, já deflagrada nos minutos iniciais do filme, Blake vaga pelos jardins à procura de algo que o espectador desconhece, porque o protagonista não fala, apenas balbucia palavras sem nexo, possivelmente tomado pelo efeito das drogas. Cambaleante e cabisbaixo, ele caminha até um quarto de vidro nos fundos do imóvel. Todo seu percurso anterior até entrar no quarto é marcado pelo som de badalos de sino. A trilha incidental se exaspera, ganha um volume quase ensurdecedor, quando Blake entra nesse recinto. Depois, à medida que o filme avança, ou estanca em círculos 
de tempo e espaço, iremos descobrir que ali será o lugar onde ele cometerá o suicídio. Naquele espaço, uma espécie de redoma de vidro, especular, adornada pelas imagens de reflexo das folhas e da luz, um lugar que parece raptar a nossa visão pelo excesso de imagens reflexivas, é ali que o filme e o músico terão um desfecho. A câmera, posicionada do lado de fora, nos leva a deslocar o olhar para a bruma sobre a bruma, do vidro sobre o vidro, do verde do filtro da câmera sobre o verde das árvores refletidas. Nessa cena, vemos, antecipada, a ausência futura do corpo de Blake.

O devir da imagem-névoa enfeixa esse olhar estetificado do corte móvel em Van Sant. Tal consciência temporal efetiva-se em função do movimento das nuvens e dos reflexos a partir dos quais são apreendidas novas camadas de realidade. Vemos, por exemplo, na Figura 2, uma composição de duplo pela ausência. Há duas pessoas dentro do carro, o empresário da gravadora e um detetive particular, travando um diálogo sobre o isolamento de Blake. No entanto, um céu branco, formado por nebulosidades - ou pelo menos assim fazendo surtir pelo seu efeito indicial projetado sobre o parabrisa - apaga a nossa visão objetiva e se coloca diante de nós à medida que o veículo avança pela estrada. Esta tomada de rarefação da imagem dura alguns minutos, com variações de visibilidade do condutor e do passageiro do veículo, mas sempre numa perspectiva espectral. Temos, portanto, por alguns segundos, quando há a completa desaparição pelas nuvens, a efemeridade de um tempo superior do sublime, o céu confrontado com os olhos humanos no ecrã cheio. Espaço que se transforma em tempo e que se desmaterializa, algo que é posto também em traços de matéria desfeita de horizonte e percepção em virtude do corte, na Figura 1, uma das fotografias de Stieglitz.

As abordagens artísticas de Stieglitz e Van Sant tratam de uma concepção temporal do espaço, uma temporalização da matéria, e, no caso do segundo Últimos Dias, ela opõe-se diametralmente ao cinema de ação desde o cinema falado a partir dos anos 1920 até os dias atuais. E, se voltarmos ao ponto de partida da fotografia que estabelecemos desde o começo deste artigo, a estética vansantiana guarda pontos de distanciamento do fotodinamismo do início do século 20, outra corrente que pregava o idealismo do movimento. A continuidade dinâmica não parece se impor como causa primeira para Van Sant, já que a repetição dos elementos é parte importante para se entender a desmaterialização dos corpos; os gestos não lhe interessam, e, sim, a desaparição dos corpos. Umberto Boccioni e os irmãos Anton Giulio e Arturo Bragaglia, pioneiros do fotodinamismo, queriam definir uma trajetória contínua das ações no espaço em uma forma única. A decomposição, a divisão e o corte são princípios que se afastam da análise futurista que eles faziam (FABRIS, 2011, p. 112). Com corte ou sem corte, com gesto ou sem gesto, trajetória física ou desmaterializada, estamos falando aqui de artistas que tentam captar a possibilidade de uma metafísica do movimento. Tal percepção visual, a de uma realidade sem compromisso com a mimese, é o que enseja a tentativa de se estabelecer pontos de contato entre Van Sant com o pictorialismo e o fotodinamismo: é que eles falam da reconfiguração do tempo. Boccioni será influenciado diretamente pelo pensamento de Bergson, pela ideia do tempo homogêneo como uma quarta dimensão do espaço. A arte, 
para ele, seria a afirmação da existência do entendimento de um puro fluxo de duração. Portanto, a fotografia artística desses movimentos de vanguarda escapa à definição da imagem como apenas uma simples testemunha do passado. Assim como o filme de Van Sant, que pela repetição do frame e da narrativa arrastada, em algumas vezes, assemelha-se ao instante fotográfico, o tempo nessas formas imagéticas dá-se pela convergência de acontecimentos (em função dos reflexos, do corte ou do dinamismo) e aquilo que se vê como fenômeno óptico. A fenda na imagem, que deixa de ser estanque, é o que vai instaurar nosso estoque de vivência e memórias afetivas.

\section{Névoa e Desaparição}

A névoa comporta-se como uma nuvem descida a Terra. Embaça a vista, torna o ambiente turvo. O olhar perde-se. De outro modo, a imagem-névoa é a multiplicação e a repetição desse olhar perdido. Ela rebate, devolve, congela, libera e reduz a velocidade perceptiva de quem a vê e está dentro dela. Trata-se de um simulacro, que explicita o próprio código do cinema. A representação de Gus Van Sant em Últimos Dias tem, assim, um caráter profundo da imagem pela imagem. Fabris, no livro Identidades Visuais - Uma leitura do retrato fotográfico comenta as observações do pesquisador italiano Paolo Bertetto acerca desse tipo de predisposição artística que testa os limites imagéticos.

A imagem que domina o horizonte metropolitano nunca é uma presença pura, e sim uma reduplicação, multiplicação, sobreposição de elementos heterogêneos, códigos, estratificações e reproduções de imagens. A imagem da imagem é uma mensagem que explicita imediatamente o próprio código, que sublinha a semelhança em detrimento da originalidade, impõe a repetição enfatizada de si, ou melhor a reprodução permanente e a auto-reprodução (FABRIS, 2004, p. 68).

A semelhança, no caso vansantiano, exacerba-se pela repetição dos gestos de Blake: ou ele está perambulando pelos jardins, movido pela resignação, ou detém-se em ensaios exaustivos no sótão do casarão, mergulhado em uma crise criativa. Mas, como lembra Fabris citando Bertetto, o artista pode romper tal indiferença da homogeneização da imagem por dois modos de simbolização - a multiplicação ou a anulação da imagem da imagem. Van Sant parece engrenar a primeira opção, à medida que abandona a função representativa para enveredar pelas possibilidades múltiplas das nuvens e seus reflexos. A imagem-névoa vansantiana, dessa forma, tem um escopo da diferença pela repetição prolongada. A indiferença passa a ser diferença quando o filme conduz a uma suspensão radical e impassível do tempo. A duração e a mudança espiritual das coisas movem a câmera a um ponto de fuga moroso, posto que Van Sant simplesmente opta por uma narrativa excessivamente vazia. Dispositivo e personagens seguem em uma ciranda 
anacrônica, em que o acontecimento é secundário ou quase nulo. A nuvem é, assim, contraditória: reflete a mis en scène dilatada em sua forma, mas também é movimento, luz condensada em corpos que caminham.

Kilpp entende o conceito de duração de Bergson na sua análise do fenômeno do Big Brother Brasil de maneira análoga a como podemos enxergar Últimos Dias. O experimento vansantiano não deixa de engendrar uma espécie de reality show, na medida em que tenta registrar a vida de Blake em "tempo real, termo que se difundiu - e contaminou nossa mirada - em grande parte pelo que se chama assim na TV: a programação ao vivo" (KILPP, 2009, p. 2). Seguimos o curso dos derradeiros dias do músico de maneira detida e voyeurística. Vemos o que ele come, com quem ele conversa, onde toma banho, as roupas femininas que veste, as pausas de reflexão e silêncio. Os "últimos dias" do protagonista não são definidos em termos de contagem cronológica. Não sabemos quanto tempo se passa, o que é flashback ou flashforward, porque a narrativa gira em círculos, de forma a anestesiar nossa consciência. Não sabemos se o tempo passa, porque a narrativa transcorre-se no presente, como observa Kilpp sobre Bergson.

É na matéria, na forma - e no pensamento - que o tempo se torna apreensível e divisível. Entretanto, esse tempo é especializado, é uma figura do tempo, um incompossível realizado na série histórica. A esses tempos apreendidos chamamos de instantes, e eles são, para Bergson, fictícios, porquanto a duração se encontra no meio, escorrendo entre tudo que imobilizamos pelo pensamento, escapando a toda simbolização (KILPP, 2009, p. 2).

O presente em Últimos Dias é, então, também um passado que não cessa de fluir. A isso Deleuze chama de devir, acontecimento puro que se dá na mudança, no movimento da memória (imagem virtual) à matéria (imagem atual). Kilpp destrincha essa chave filosófica, que é plena abertura para se entender o emaranhado de tempo no filme vansantiano. Há, no entanto, um ponto de discordância deste artigo em relação aos posicionamentos da pesquisadora, quando ela diz que não existe imagem do tempo duração no cinema. Kilpp parte do pressuposto de que a TV trabalha com imagens produzidas de forma linear e que sofrem interferências da montagem artificial de molduras simultâneas na tela, que assim chama de molduras televisivas, criando a coalescência de tempos-duração. Porém, entendemos que é puramente discernível, embora de maneira distinta aos processos da TV, essa intervenção de um tempo externo na imagem vansantiana. Ora, estamos falando de um tempo passado que é reproduzido como presente na vida de Blake. Esse decurso cênico é amparado pela suspensão das nuvens, compreendendo uma macroestrutura estética com microfios de tempo: ela é movimento de câmera e, ao mesmo tempo, reflexo simultâneo na imagem.

Um exemplo de que existe imagem-duração em Últimos Dias é o momento em que Blake decide ensaiar mais uma vez no sótão. A diferença, desta vez, é que Van Sant decide 
filmar a cena de fora para dentro, tomando a perspectiva da janela. Ele faz essa tomada em uma das cenas mais arrastadas, em um único plano-sequência, portanto sem corte, com duração de cinco minutos e 34 segundos. O único movimento de câmera efetua-se em um lento zoom out, tendo como ponto de partida a janela do lado de fora até a uma visão macro da casa, com uma árvore frondosa ao lado da janela. A composição final do último enquadramento revela um dia ensolarado, possivelmente em um horário próximo ao meio-dia. Nesta cena, há um duplo compósito de tempo. Vemos, na Figura 3, a construção de duas molduras de percepção visual dentro da janela, esta uma moldura-mor. A primeira, acima, é o espectro névoa, com o fluxo puro do tempo único. Ali, escorre uma enxurrada calma e silenciosa de um tempo-mater, aquele que origina e refunda. A representação simbólica que vimos compõe-se de galhos verdes, refletidos no vidro da janela. Símbolo da árvore vizinha à parede da casa, a imagem permite a leitura indicial das nuvens, já que por trás da copa está o céu de cor branca. O movimento dos galhos se assemelha a uma massa gasosa no céu, que some e desvanece em um dado momento, e em outro ela se refaz, condensa, sendo, assim, transformação constante. A névoa faz-se presente, sobretudo, na desaparição. Logo abaixo a essa moldura, há outra, ainda dentro da mesma janela, com o acontecimento da pré-morte de Blake, o desvario e o tempo caótico do jovem rapaz. Este é o primeiro compósito, puramente fotográfico. Na Figura 4 , podemos vislumbrar a segunda situação, desta vez empreendida pelo cinema em sua natureza particular, que é o movimento de afastamento lento da câmera. O espectador, até então limitado visualmente pelas molduras, terá o horizonte ampliado em virtude do prolongamento das bordas do quadro do filme. O cenário revela-se, a árvore torna-se matéria, outra janela aparece e o ruído cresce.

A imagem-névoa é esse distanciamento: visão objetiva, que investe o olhar sobre o objeto conjugando cristais de tempo, a imagem cristal como a virtualização perfeita do futuro que já o pertence e o passado que ainda não o deixou de ser, atualizados no presente pelo olhar (DELEUZE, 2005, p. 88). Não apenas imagem, essa composição heterogênea de tempos, sutil condensação de nuvens, também é sonora: escutamos a voz de Blake e a música, passado e futuro implodidos em suas definições lineares e convertidos em fios de memória.

Enquanto há essa preocupação de uma metafísica do corpo e da imagem em Últimos Dias, concorre outro esforço de Van Sant em desfigurar a identidade por uma essência do sujeito. Na forma como o diretor estabelece as filmagens, cria-se um despojamento do modelo na atuação dos atores. Trata-se, em suma, de uma arte da desaparição. Michael Pitt, em cenas comuns, apartadas da imagem-névoa, é sondado por uma câmera que não se preocupa em desvendar o aspecto mítico ou de gênio que o levou a não suportar mais a vida. Pelo contrário, suas ações são documentadas pelo que há de mais banal. Outros personagens que habitam a casa, os amigos de Blake e os estranhos que circulam por ela, passam pelo mesmo processo, em que a empatia e a interação com a câmera colocam-se em primeiro plano. Eles são filmados conversando amenidades, fazendo sexo e assumindo gestos de uma marca identitária da juventude, a ideia de uma máscara que 
não é revelada em seu conteúdo, mas em sua aparência simples. Andy Warhol, mestre de uma espécie de anestesia advinda da banalização da imagem na pop art, é um dos pilares de influência para Van Sant, e tem essa estética refletida no filme. Warhol supervalorizava a imagem sob o signo do consumo, suas imagens evidenciavam "uma superfície de aparição, de figuração, uma superfície virtual graças à qual o mundo impõe sua descontinuidade" (FABRIS, 2004, p. 76).

O corpo nu de Blake é evidenciado em várias cenas, incluindo a de abertura, um longo plano-sequência na floresta em que o protagonista urina em um lago, de costas para o espectador, resultando em uma encenação narcísica do corpo e do belo. A nudez repete-se na última tomada do filme, quando, ao morrer, o espírito do rapaz desencarna e sobe em direção ao céu. Novamente, os reflexos se multiplicam, a câmera se posiciona atrás da redoma de vidro e a luz se refrata. Mas, aqui, na Figura 5, o corpo nu encenado não se aproxima de um corpo sensual e dessublimado, e, sim, aponta para uma elevação da alma, com a matéria desencarnada. O desfecho parece indicar uma maneira que Van Sant busca para se redimir, após o corpo, ele dá vazão a coisas do espírito.

\title{
Considerações finais
}

A imagem-névoa é a materialização estética de uma construção do tempo fílmico de Gus Van Sant, que parece expressar uma vontade de aprisionar a realidade pelas imagens. Ela pode ser presença material, árvores frondosas refletidas na janela. Também pode ser etérea, cosmogonia de uma ausência, a desaparição de quem está por trás do parabrisa de um carro. O que importa é a imagem e o seu tempo puro. Imagem por uma imagem frívola, comodificada, de desaparição da matéria e também da identidade e do sujeito. A imagem-névoa, como o fetiche de um clichê, é também máscara. É o rosto decupado visualmente para o bel-prazer da memória imagética, o alívio para a quase morte.

Tentar captar o passado por imagens é um ato nebuloso, de nuvens cúmulo-nimbos. Van Sant aponta, em Últimos Dias, que o espectro da nuvem é também o que o aprisiona. Parece uma faina proustiana, como explica Susan Sontag acerca de uma memória que é acionada involuntariamente, as migalhas visuais em vez do gosto das madeleines:

\begin{abstract}
A estratégia do realismo de Proust presume a distância daquilo que é normalmente experimentado como real, o presente, a fim de reanimar aquilo que em geral se pode alcançar apenas de forma remota e nebulosa, o passado - que é onde o presente se torna real no sentido de Proust, ou seja, algo que pode ser possuído (SONTAG, 2004, p. 180).
\end{abstract}

Van Sant tensifica a sua relação com o cinema neste filme, nessa tentativa de narrar algo, mas solto em um campo enunciativo. A imagem pela imagem deixa entrever outro caminho, a fluidez de uma mis en scène que é própria névoa em si: leve, gasosa, delicada. 
Opta pela corporificação do fenômeno imagético, o corte transformado em devir-janela, que resulta na desmaterialização (morte simbólica e real) de Blake: o tempo que é cristal suspenso no ar. Matéria que é revestida de névoa, de tempo que corta o céu, inescapável às mãos, mas não à câmera.

\section{Referências}

BOUQUET, Stéphane; LALANNE, Jean-Marc. Gus Van Sant. Paris: Éditions Cahiers du cinéma, 2009.

CARRIÈRE, Jean-Claude. A Linguagem secreta do cinema. Rio de Janeiro: Nova Fronteira, 2006.

DELEUZE, Gilles. A Imagem-movimento (Cinema 1). São Paulo: Brasiliense, 1983.

. A Imagem-tempo (Cinema 2). São Paulo: Brasiliense, 2005.

DUBOIS, Philipe. O Ato fotográfico e outros ensaios, tr. M.Appenzeller, Campinas, Papirus, (1990) 2004.

FABRIS, Annateresa. O Desafio do olhar: fotografia e artes visuais no período das vanguardas históricas, vol. 1, SP, WMF Martins Fontes, 2011, col. Arte \& Fotografia.

. Identidades visuais: uma leitura do retrato fotográfico, BH, UFMG, 2004.

KILPP, Suzana. Imagens médias do tempo-acontecimento televisivo. In: Compós, $18^{\mathrm{a}}$ ed., 2009, Belo Horizonte. Disponível em: <www.suzanakilpp.com.br/artigos/Imagens_Medias_do_Tempo_Acontecimento_Televisivo.pdf >. Acesso em 08/04/2013.

. Panoramas especulares. Universidade do Vale do Rio dos Sinos (Unisinos), Porto Alegre, 2005. Disponível em: < http://www.suzanakilpp.com.br/artigos/Panoramas_Especulares.pdf $>$. Acesso em 08/04/2013.

PARISH, James Robert. Gus Van Sant - An unauthorized biography. New York: Thunder's Mouth Press, 2001.

SONTAG, Susan. Sobre a fotografia. São Paulo: Companhia das Letras, 2004.

VAN SANT, Gus, Últimos Dias, Estados Unidos: 2005. 97 minutos. 